\title{
Jahrestagung 1999
}

Vom 6. bis 9. Oktober 1999 hielt die Vereinigung der Deutschen Staatsrechtslehrer ihre Jahrestagung in Heidelberg $a b$, wo sie vor fünfzig Jahren, 1949, wiedergegründet worden ist, nachdem 1931 die letzte Jahrestagung der 1922 gegründeten Vereinigung abgehalten worden war. Während der Mitgliederversammlung gedachte die Vereinigung ihrer seit der Potsdamer Tagung verstorbenen Mitglieder Joseph H. Kaiser und Joachim Burmeister sowie ihres langjährigen Mitgliedes Carl Hermann Ule. Die Vereinigung wird das Andenken der Verstorbenen in Ehren halten. Der Vorsitzende hieß 25 neue Mitglieder willkommen, die sich kurz vorstellten. Damit zählt die Vereinigung jetzt 470 Mitglieder.

$\mathrm{Zu}$ Mitgliedern des Vorstandes für das Jahr 2000 wurden gewählt: Jochen Abr. Frowein, Jörn Ipsen, Hartmut Bauer. § 4 der Satzung wurde dahin geändert, daß der Vorstand auf zwei Jahre gewählt wird. Diese Regelung gilt ab 1. Oktober 2001.

Am ersten Abend fand in der Alten Universität, dem Tagungsort der Vereinigung, ein Empfang durch den Prorektor der Universität, Professor Dr. Heinz-Dietrich Lözee, statt. In seiner Erwiderung auf die Begrüßungsworte des Prorektors sprach der Vorsitzende über die Bedeutung der Heidelberger Fakultät für die Vereinigung, über die Bemühungen vor allem Walter Jellineks um die Wiedergründung der Vereinigung und über die herausragende Bedeutung der Heidelberger Fakultät im 19. Jahrhundert, insbesondere auch für die systematisch und methodisch betriebene Rechtsvergleichung.

$\mathrm{Zu}$ Beginn des wissenschaftlichen Teils der Verhandlungen hielt der Vorsitzende eine Ansprache zum Jubiläum der Vereinigung. Die Ansprache leitet den vorliegenden Band ein. Die Beratungsgegenstände, zu denen je drei Berichte erstattet wurden, waren am Donnerstag „Arbeitsmarkt und staatliche Lenkung " und am Freitag "Staat und Religion ". Mit dem ersten Thema wandte sich die Vereinigung seit langem wieder einmal wirtschaftsverfassungsrechtlichen Problemen zu wie schon 1952, 1968 und 1976. Vorläufer des zweiten Themas waren 1952 das „Staatskirchen-

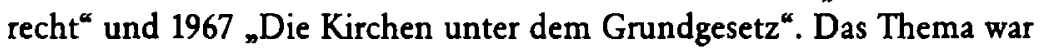
aber breiter angelegt, so daß auch Probleme erörtert werden konnten, die Religionen betreffen, die nicht in Kirchen organisiert sind. Da die Wanderungsbewegungen in und nach Europa uns mit neuartigen religiösen Phänomenen versorgt haben, schien es von Interesse zu erfahren, wie an- 
dere Verfassungsstaaten mit diesen Problemen umgehen. Deshalb war ein rechtsvergleichender Bericht in Auftrag gegeben worden. Entsprechendes galt für das erste Thema.

Der Gesprächskreis Verwaltungslehre tagte am Mittwoch, dem 6. Oktober, erstmals unter der Leitung des neuen Vorsitzenden Herrn Bull. Herr Professor Dr. Werner Jann (Sozialwissenschaftliche Fakultät der Universität Potsdam) und Herr Siedentopf referierten über die Bedeutung der Verwaltungskultur für die Umsetzung des Europäischen Gemeinschaftsrechts. Gleichzeitig tagte der 1998 neugebildete Arbeitskreis „Europäisches Verfassungsrecht ${ }^{\star}$ unter Leitung seines Vorsitzenden, Herrn E. Klein. Die Herren Heintzen, Koenig, Ress und Zuleeg erörterten in einem Podiumsgespräch „Richterwahl und Legitimation zur Rechtsfortbildung - EuGH, EGMR und BVerfG im Vergleich".

Am Donnerstag abend fand im Schloß ein Empfang des Landes BadenWürttemberg und der Stadt Heidelberg statt. Vertreten war das Land durch Herrn Minister Müller und die Stadt durch Herrn Bürgermeister Dr. Beß. Der gesellige Abend am Freitag begann mit musikalischen Darbietungen der Pfifferari di Santo Spirito, die nach den ernsten wissenschaftlichen Beratungen die Gemüter der Zuhörer angenehm auflockerten. Der Ausflug am Samstag führte in den Odenwald, wo alternativ die Einhartsbasilika, Michelstadt oder das Schloß Erbach besichtigt werden konnte.

Die Vereinigung schuldet Reinbard Mußgnug, dem kooptierten Vorstandsmitglied, und seinen Mitarbeitern großen Dank für die vorzügliche Organisation der Tagung. Frau Dr. Mußgnug hat sich sehr verdient gemacht um die Planung und Koordination des reichen Begleitprogramms - Natur, Kunst, Technik, wissenschaftliche und soziale Institutionen -, das die Ehegattinnen der Heidelberger Kollegen betreut haben.

C. S. 